\title{
The influence of mouthrinses and simulated toothbrushing on the surface roughness of a nanofilled composite resin
}

\author{
Keico Graciela Sano Trauth ${ }^{(a)}$ \\ Ana Paula Terossi de Godoi ${ }^{(a)}$ \\ Vivian Colucci ${ }^{(b)}$ \\ Silmara Aparecida Milori \\ Corona $^{(b)}$ \\ Alma Blásida Concepción Elizaur \\ Benitez Catirse ${ }^{(a)}$
}

\footnotetext{
(a) Department of Dental Materials and Prosthodontics, Ribeirão Preto School of Dentistry, University of São Paulo, Ribeirão Preto, SP, Brazil.

(b) Department of Operative Dentistry, Ribeirão Preto School of Dentistry, University of São Paulo, Ribeirão Preto, SP, Brazil.
}

Declaration of Interests: The authors certify that they have no commercial or associative interest that represents a conflict of interest in connection with the manuscript.

Corresponding author:

Keico Graciela Sano Trauth

E-mail:keicosano@usp.br

Received for publication on Sep 30, 2011 Accepted for publication on Feb 01, 2012
Abstract: The aim of this study was to determine the influence of mouthrinses on the surface roughness of a nanofilled composite resin after toothbrushing. One hundred nanofilled composite resin specimens were prepared and randomly distributed into two groups - brushed and non-brushed - and then assigned to five subgroups, according to the mouthrinse solutions $(n=10)$ : Colgate Plax Fresh Mint, Oral B, Cepacol, Colgate Plax, and artificial saliva. Each sample was immersed in $20 \mathrm{~mL}$ of the mouthrinses for 1 minute, 5 days per week, twice a day, for a 3-week period. The control group used in the study was one in which the specimens were not subjected to brushing and remained only in artificial saliva. Toothbrushing was performed once a week for 1 minute, for 3 weeks. Surface roughness measurements (Ra) were performed after the immersion period and toothbrushing, by means of a profilometer. Data were analyzed by two-way ANOVA and Tukey's test. Analysis revealed that the association between toothbrushing and Colgate Plax Fresh Mint produced the lowest surface roughness $(\mathrm{p}<0.05)$. All other groups tested (Oral B, Cepacol, Colgate Plax, artificial saliva) exhibited no statistically significant differences between surfaces, whether subjected to toothbrushing or not $(\mathrm{p}<0.05)$. It was concluded that the surface roughness of the nanofilled composite resin tested can be influenced by the mouthrinse associated with toothbrushing.

Descriptors: Composite Resins; Surface Properties; Toothbrushing; Mouthwashes.

\section{Introduction}

Dental caries is a multifactorial disease. Its development depends on several variables, such as the presence of microorganisms, the substrate, the host's oral environment, and time. ${ }^{1}$ Proper oral hygiene accomplished by toothbrushing is the primary means of preventing enamel demineralization. However, in patients with gingivitis and periodontitis, ${ }^{2}$ or in those wearing extensive splinting or fixed prostheses, orthodontic appliances, overdentures, and implant-supported restorations ${ }^{3}$, the use of mouthrinses should complement toothbrushing.

Wear from toothbrushing can influence the mechanical and optical properties of composite resins. The surface roughness can increase due to the abrasion of the polymer matrix, subsequently followed by filler exposure, and finally loosening of filler particles. ${ }^{4}$

In addition, mouthrinses can contain alcohol and other substances, such as detergents, emulsifiers, and organic acids, that can lead to the degradation of the composite resin surface. ${ }^{5}$ According to Gürgan et al., ${ }^{6}$ mouthrinses can af- 
fect the hardness of restorative materials. Alcohol content is not the only factor that has a softening effect on the materials: Saliva, for example, can dilute or concentrate mouthrinses, increasing or decreasing this effect.

Recently, nanofilled composites were introduced in an attempt to provide a restorative material that could be used in both anterior and posterior areas, associating high initial polishing with superior polish and gloss retention. ${ }^{4,7}$ There is still much to be learned about this resin. Our study hypothesis was that the surface roughness increases with the use of mouthrinse solutions when associated with toothbrushing.

Therefore, the aim of this study was to determine the influence of mouthrinses on the surface roughness of a nanofilled composite resin after toothbrushing.

\section{Methodology}

Experimental design

The factors under study were toothbrushing in two levels:

- Group A, brushed,

- Group B, non-brushed;

and mouthrinse in five levels:

- Colgate Plax Fresh Mint,

- Oral B,

- Cepacol,

- Colgate Plax, and

- artificial saliva

The sample size was determined after an experimental pilot trial and standard deviations of the results were set at $\mathrm{n}=10$. The experimental sample was comprised of 100 composite resin specimens. The response variable was surface roughness performed before and after experimental periods, with a profilometer.

\section{Preparation of specimens}

One hundred specimens were prepared with a nanofilled composite resin (Filtek Supreme, shade A2, 3M ESPE, São Paulo, Brazil). The composite resin was manipulated according to the manufacturer's instructions and inserted into a stainless steel matrix $(6 \mathrm{~mm}$ diameter and $2 \mathrm{~mm}$ depth). After the matrix was filled, a polyester strip (KDent, Inc., St. Louis, USA) was pressed onto the surface with a glass slab (1 kg weight) to smooth the material surface. After 30 seconds, the glass slab was removed, and the composite resin was light-cured in a LED light-curing unit with power output of $750 \mathrm{~mW} /$ $\mathrm{cm}^{2}$ (UltraLED, Dabi Atlante, Ribeirão Preto, Brazil) for 40 seconds. The cured specimens were removed and maintained for $24 \mathrm{~h}$ in $100 \%$ relative humidity at $37^{\circ} \mathrm{C}$. After 24 hours, the specimens were subjected to surface polishing with abrasive disks without continuous water irrigation (Sof-Lex, 3M ESPE, St. Paul, USA) in decreasing order of abrasiveness $(10 \mathrm{~s}$ each $),{ }^{8}$ in a slowspeed handpiece.

\section{Immersion in mouthrinses}

In the selection of mouthrinses, two main characteristics were considered: the presence of alcohol and dyes. The specimens were randomly allocated into five subgroups according to the mouthrinses:

- Colgate Plax Fresh Mint (Colgate/Palmolive, São Bernardo do Campo, SP, Brazil),

- Oral B (Procter \& Gamble, Brazil),

- Cepacol (Aventis Pharma, São Paulo, Brazil),

- Colgate Plax (Colgate/Palmolive, São Bernardo do Campo, Brazil), and

- artificial saliva (made by a compounding pharmacy). (More specifications are listed in Table 1.)

During 3 weeks, each sample was immersed in $20 \mathrm{~mL}$ of mouthrinse for 1 minute under constant agitation in a magnetic agitator, 5 days per week, twice a day (12-hour interval between exposures). ${ }^{5}$ After each immersion, the specimens were rinsed with water and then stored in distilled water at $37^{\circ} \mathrm{C}^{8}$ until the next immersion.

\section{Brushing}

Brushing was carried out by means of a toothbrushing machine, following the ISO/DTS 145692 specifications for wear testing (Mavtec Comércio Ltda., Ribeirão Preto, Brazil). ${ }^{9}$ The machine allows six specimens to be brushed simultaneously. The brushing was performed at a speed of $356 \mathrm{rpm}$, with a dentifrice slurry (Colgate Total and distilled water, 1:1 ratio). The track covered by the brush was $3.8 \mathrm{~cm}$, and the toothbrushing load was standardized at $200 \mathrm{~g}^{10}$

The toothbrushes were cut at the neck and fixed by screws at both sides and the top of the brush support. 
Table 1 - Immersion solutions used in this study.

\begin{tabular}{c|c|c|c|c}
\hline Mouthrinses & Composition & $\mathrm{pH}$ & Alcohol \% & Manufacturer \\
\hline $\begin{array}{c}\text { Colgate Plax } \\
\text { Fresh Mint }\end{array}$ & $\begin{array}{c}\text { Triclosan (0.03\%), sodium fluoride } \\
(225 \mathrm{ppm}), \text { copolymer PVM/MA } \\
(0.020 \%), \text { ethyl alcohol, dye }\end{array}$ & 6.6 & $6 \%$ & $\begin{array}{c}\text { Colgate-Palmolive } \\
\text { Brazilian industry }\end{array}$ \\
\hline Oral-B & $\begin{array}{c}\text { Olysorbate 20, flavor, methylparaben } \\
(0.053 \%), \text { sodium fluoride (226 ppm) } \\
\text { sodium saccharin, sodium benzoate, } \\
\text { propylparaben, dye }\end{array}$ & 5.36 & - & $\begin{array}{c}\text { Laboratories Rety } \\
\text { Colombian } \\
\text { industry }\end{array}$ \\
\hline Cepacol & $\begin{array}{c}\text { Cetylpyridinium chloride, sodium } \\
\text { phosphate, sodium saccharin, disodium } \\
\text { EDTA, polysorbate, glycerin, alcohol }\end{array}$ & 7.29 & $14.5 \%$ & $\begin{array}{c}\text { Sanofi-Aventis } \\
\text { Brazilian industry }\end{array}$ \\
\hline $\begin{array}{c}\text { Aqua, glycerin, propylene glycol, } \\
\text { sorbitol, PEG-40 hydrogenated castor oil, } \\
\text { sodium cetylpyridinium chloride, sodium } \\
\text { saccharin, sodium fluoride (225 ppm } \\
\text { fluor) }\end{array}$ & 6.73 & - & $\begin{array}{c}\text { Colgate-Palmolive } \\
\text { Brazilian industry }\end{array}$ \\
\hline salificial & $\begin{array}{c}\text { Nipacin, carboxymethyl, KCl, NaCl, } \\
\text { MgCl, CaCl, cellulose, sorbitol and } \\
\text { deionized water }\end{array}$ & 6.8 & - & $\begin{array}{c}\text { Doce Erva } \\
\text { (Compounding } \\
\text { and homeopathic } \\
\text { pharmacy) }\end{array}$ \\
\hline
\end{tabular}

Correct adjustment of the screws allowed for proper leveling of the toothbrush. Each specimen was subjected to toothbrushing with a soft toothbrush (Condor Plus, Condor SA, São Bento do Sul, Brazil). The specimens were brushed weekly for 1 minute, during a period of 3 weeks ( 0.356 cycles) ${ }^{10}$ corresponding to brushing for one week, two times per day.

The control group used in the study was one in which the specimens were not subjected to brushing and remained only in artificial saliva.

\section{Surface roughness analysis}

The first specimens were subjected to surface roughness measurements after surfaces were polished. The other readings were performed on the $7^{\text {th }}, 14^{\text {th }}$, and $21^{\text {st }}$ days. The surface roughness of each specimen was determined by means of a profilometer (Surfcom 480A, Tokyo Seimitsu Co., LTD., Tokyo, Japan). Three scans were performed for each specimen. The stylus speed was $0.6 \mathrm{~mm} / \mathrm{second}$, cut-off was set to $0.25 \mathrm{~mm}$, and the average roughness values were recorded $(\mathrm{Ra})$.

\section{Statistical analysis}

Two-way ANOVA and Tukey's test were performed (5\% significance level). Statistical calculations were made with GMC software (Version 2002, available at http://www.forp.usp.br/restauradora/gmc/gmc. html\#gmc, Ribeirão Preto, Brazil).

\section{Results}

Two-way ANOVA revealed significant interaction between toothbrushing and mouthrinses $(p=0.0034)$. Tukey's test revealed that the association between Colgate Plax Fresh Mint and toothbrushing resulted in the lowest surface roughness. All other groups tested (Oral B, Cepacol, Colgate Plax, artificial saliva) exhibited no statistically significant differences between surfaces, whether subjected to toothbrushing or not $(p>0.05)$. Mean values for all groups are presented in Table 2.

\section{Discussion}

Degradation of composite materials can occur due to mechanical and chemical factors from the oral environment, which can cause changes in surface roughness, ${ }^{11}$ loss of surface gloss, and increased discoloration of the material, ${ }^{12}$ affecting the esthetic quality of the restoration. These changes have been attributed to the degradation of the polymer matrix, or the resin-filler interface, and loss of inorganic filler particles. ${ }^{11,13,14}$ In non-stressbearing areas, the main causal factors of texture changes are the relationship between biodegradation and oral hygiene procedures..$^{15}$ Thus, regular prophylactic procedures, such as toothbrushing, the use of mouthrinses, or a combination of these, may produce deleterious side- 
Table 2 - Mean and standard deviation of surface roughness $(\mathrm{Ra})$ of composite resins.

\begin{tabular}{c|c|c|c|c|c}
\hline \multirow{2}{*}{ Toothbrushing } & \multicolumn{5}{|c}{ Mouthrinses } \\
\cline { 2 - 6 } & $\begin{array}{c}\text { Colgate Plax } \\
\text { Fresh Mint }\end{array}$ & Oral B & Cepacol & Colgate Plax & $\begin{array}{c}\text { Artificial } \\
\text { Saliva }\end{array}$ \\
\hline Brushed & $0.319 \mathrm{Ab}$ & $0.410 \mathrm{ABa}$ & $0.582 \mathrm{Ba}$ & $0.576 \mathrm{Ba}$ & $0.493 \mathrm{ABa}$ \\
\hline Unbrushed & $0.667 \mathrm{Aa}$ & $0.498 \mathrm{Aa}$ & $0.484 \mathrm{Aa}$ & $0.642 \mathrm{Aa}$ & $0.649 \mathrm{Aa}$ \\
\hline
\end{tabular}

$\mathrm{SD} \pm 0.04$. Different capital letters represent differences within rows. Different lowercase letters represent significant differences within columns.

effects on the surface and physical properties of restorative materials. ${ }^{16}$ However, information evaluating the potential effects of mouthrinses associated with toothbrushing of composite resins is needed, because this could affect the maintenance of the surface smoothness of the restoration.

Similar surface roughness of the composite was observed whether or not toothbrushing was associated with the mouthrinses, except one type of mouthrinse (Colgate Plax Fresh Mint). The nanofilled composite resin used in this study presented moderate wear and surface roughness. ${ }^{4}$

The degradation of resin composites is a complex mechanism that depends on the characteristics of the composite, such as the size, ${ }^{17}$ volume and type of inorganic filler, ${ }^{2,418}$ matrix composition, and degree of conversion. ${ }^{19}$ The most likely explanation for degradation is the presence of nanosized particles $(5-20 \mathrm{~nm})$ throughout the resin matrix, ${ }^{7}$ which results in less space between the particles, and ultimately more protection of the softer resin matrix ${ }^{4,20}$ and less filler plucking, ${ }^{20}$ compared with other types of resins. This leads to lower resin porosity ${ }^{21}$ and improved abrasion resistance of the material. ${ }^{4,21}$

Conversely, the types and volumes of inorganic fillers also influence the degradation, which in turn results in higher or lower material solubility. Theoretically, a larger total surface area of nanofilled particles with nonagglomerated $20 \mathrm{~nm}$ silica fillers allows more water to accumulate at the filler particle-polymeric matrix interfaces, thus increasing salivary sorption and solubility. ${ }^{17}$

The monomer type also directly influences the potential water sorption of the material. Monomers like UDMA, Bis-GMA, and TEGDMA contain polar groups such as - $\mathrm{OH}-,-\mathrm{O}-$, and -NH-. These groups increase the material's hydrophilicity, ${ }^{19}$ probably making it more prone to salivary sorption, ${ }^{17}$ however, these factors cannot be considered to influence this study, since they were standardized for all groups.

The dentifrice used in this study (Colgate Total, RDA 70) was of low abrasion, ${ }^{12}$ being more gentle to the composite surface. It has been found that the major factors influencing abrasion are dentifrice and toothbrush characteristics. ${ }^{4}$ Factors related to dentifrice are the type of abrasive, sizes of particles, and the dilution proportion, while factors related to the toothbrush are the number, stiffness, and shapes of tufts and bristles. ${ }^{4}$ In addition, a soft toothbrush was used to promote low abrasion. ${ }^{22}$ As a rule, the correlation between the toothbrush filament diameter and abrasion was lower than the correlation between toothpaste abrasiveness and resulting abrasion, and this should be considered. ${ }^{23}$ This demonstrates that abrasion of composite resins is affected more by the toothpaste's abrasiveness than by the toothbrush filament diameter. ${ }^{23}$ Although dentifrice is used for low abrasion and the brush is soft, the joint action of these can justify the higher values found for most groups subjected to brushing in comparison with the non-brushed groups.

Another factor that could affect the resulting surface roughness of the composite resin is the mouthrinse. This study revealed that the result was not dependent upon the type of mouthrinse used. Artificial saliva and the non-alcohol mouthrinse solution (Oral B) presented statistically similar surface roughness values. However, the values of surface roughness for Colgate Plax Fresh Mint, which contains less alcohol (6\%), were lower than those for Cepacol and Colgate Plax, which contain $14.5 \%$ and $8.7 \%$ alcohol, respectively. Regarding the $\mathrm{pH}$, the lowest value was for Oral B (5.36), and the highest was found for Cepacol (7.29). These differences may account for the different behavior of the resins when subjected to different mouthrinses. It has been found that low-pH mouthrinses with higher alcohol content may affect some physical-mechanical properties of resin composites, producing softening of esthetic restorative 
materials. ${ }^{24}$ Therefore, the role of $\mathrm{pH}$ was not as clear during the test period, and longer storage periods may result in statistically significant differences. ${ }^{11}$

Different results of surface roughness have been obtained in other studies. ${ }^{11,12}$ In our study, the specimens were immersed in artificial saliva during the experimental period. The leaching pattern has been shown to be consistent for at least one year, and was more evident for composites stored in artificial saliva than for those stored in distilled water. ${ }^{25}$ This procedure may also influence roughening from toothbrushing, because the saliva contains specific proteins and ions that may diminish the roughening effect of the toothbrush; ${ }^{16}$ however, despite all of that, this study showed higher roughness values resulting from immersion in saliva compared with Colgate Plax Fresh Mint.

It is important to notice that the pattern of toothbrushing wear on restorative materials is the result of the interaction of several factors, and studies have reported the effects on other restorative materials such as glass-ionomer cements, pit and fissure sealants, resinmodified glass ionomers, and ceramics. Further research on clinical conditions should be performed to confirm the results obtained in this laboratory study.

\section{Conclusions}

Within the limitations of this in vitro study, we concluded that the surface roughness of a nanofilled composite resin can be influenced by mouthrinse solutions when it is associated with toothbrushing; however, mouthrinse by itself does not affect the surface rough-

9. Richmond R, Macfarlane TV, McCord JF. An evaluation of the surface changes in PMMA biomaterial formulations as a result of toothbrush/dentifrice abrasion. Dent Mater. 2004 Feb;20(2):124-32.

10. Pisani MX, Bruhn JP, Paranhos HF, Silva-Lovato CH, de Souza RF, Panzeri H. Evaluation of the abrasiveness of dentifrices for complete dentures. J Prosthodont. 2010 Jul;19(5):369-73.

11. Voltarelli FR, dos Santos-Daroz CB, Alves MC, Cavalcanti AN, Marchi GM. Effect of chemical degradation followed by toothbrushing on the surface roughness of restorative composites. J Appl Oral Sci. 2010 Dec;18(6):585-90.

12. Costa J, Adams-Belusko A, Riley K, Ferracane JL. The effect of various dentifrices on surface roughness and gloss of resin composite. J Dent. 2010;38(Suppl 2):e123-8. ness of composite resins.

\section{Acknowledgement}

This study was supported by the National Council for Scientific and Technological Development (CNPq) of Brazil.

\section{References}

1. Ferraro M, Vieira AR. Explaining gender differences in caries: a multifactorial approach to a multifactorial disease. Int J Dent. 2010 Mar;2010:649643. doi:10.1155/2010/649643.

2. Almeida GS, Poskus LT, Guimarães JG, da Silva EM. The effect of mouthrinses on salivary sorption, solubility and surface degradation of a nanofilled and a hybrid resin composite. Oper Dent. 2010 Jan-Feb;35(1):105-11.

3. Ciancio SG. Use of mouthrinses for professional indications. J Clin Periodontol. 1988 Sep;15(8):520-3.

4. Moraes RR, Ribeiro D dos S, Klumb MM, Brandt WC, CorrerSobrinho L, Bueno M. In vitro toothbrushing abrasion of dental resin composites: packable, microhybrid, nanohybrid and microfilled materials. Braz Oral Res. 2008 Apr-Jun;22(2):112-8.

5. Colucci V, dos Santos CD, do Amaral FL, Corona SA, Catirse $\mathrm{AB}$. Influence of $\mathrm{NaHCO} 3$ powder on translucency of microfilled composite resin immersed in different mouthrinses. J Esthet Restor Dent. 2009 Aug;21(4):242-50.

6. Gürgan S, Onen A, Köprülü H. In vitro effects of alcohol-containing and alcohol-free mouthrinses on microhardness of some restorative materials. J Oral Rehabil. 1997 Mar;24(3):244-6.

7. Mitra SB, Wu D, Holmes BN. An application of nanotechnology in advanced dental materials. J Am Dent Assoc. 2003 Oct;134(10):1382-90.

8. Nagem Filho H, D’Azevedo MT, Nagem HD, Marsola FP. Surface roughness of composite resins after finishing and polishing. Braz Dent J. 2003;14(1):37-41.

13. Larsen IB, Munksgaard EC. Effect of human saliva on surface degradation of composite resins. Scand J Dent Res. 1991 Jun;99(3):25461.

14. Yap AU, Wattanapayungkul P, Chung SM. Influence of the polymerization process on composite resistance to chemical degradation by food-simulating liquids. Oper Dent. 2003 Nov-Dec;28(6):723-7.

15. Cho LR, Yi YJ, Heo SJ. Effect of tooth brushing and thermal cycling on a surface change of ceromers finished with different methods. J Oral Rehabil. 2002 Sep;29(9):816-22.

16. Heintze SD, Forjanic M, Ohmiti K, Rousson V. Surface deterioration of dental materials after simulated toothbrushing in relation to brushing time and load. Dent Mater. 2010 Apr;26(4):306-19.

17. da Silva EM, Almeida GS, Poskus LT, Guimarães JG. Relationship between the degree of conversion, solubility and salivary sorption 
of a hybrid and a nanofilled resin composite. J Appl Oral Sci. 2008 Mar-Apr;16(2):161-6.

18. Yeh ST, Wang HT, Liao HY, Su SL, Chang CC, Kao HC, et al. The roughness, microhardness, and surface analysis of nanocomposites after application of topical fluoride gels. Dent Mater. 2011 Feb;27(2):187-96.

19. Gonçalves L, Noronha Filho JD, Guimarães JG, Poskus LT, Silva EM. Solubility, salivary sorption and degree of conversion of dimethacrylate-based polymeric matrixes. J Biomed Mater Res B Appl Biomater. 2008 May;85(2):320-5.

20. Moraes RR, Gonçalves LS, Lancellotti AC, Consani S, CorrerSobrinho L, Sinhoreti MA. Nanohybrid resin composites: nanofiller loaded materials or traditional microhybrid resins? Oper Dent. 2009 Sep-Oct;34(5):551-7.

21. Jørgensen KD. Restorative resins: abrasion vs. mechanical properties. Scand J Dent Res. 1980 Dec;88(6):557-68.

22. Harte DB, Manly RS. Effect of toothbrush variables on wear of dentin produced by four abrasives. J Dent Res. 1975 SepOct;54(5):993-8.

23. Wiegand A, Kuhn M, Sener B, Roos M, Attin T. Abrasion of eroded dentin caused by toothpaste slurries of different abrasivity and toothbrushes of different filament diameter. J Dent. 2009 Jun;37(6):480-4.

24. Gurdal P, Güniz AB, Hakan SB. The effects of mouthrinses on microhardness and colour stability of aesthetic restorative materials. J Oral Rehabil. 2002 Sep;29(9):895-901.

25. Söderholm KJ, Yang MC, Garcea I. Filler particle leachability of experimental dental composites. Eur J Oral Sci. 2000 Dec;108(6):555-60. 